\title{
Lateral Habenula Stimulation Inhibits Rat Midbrain Dopamine Neurons through a $\mathrm{GABA}_{\mathrm{A}}$ Receptor-Mediated Mechanism
}

\author{
Huifang Ji and Paul D. Shepard \\ Maryland Psychiatric Research Center and Department of Psychiatry, University of Maryland School of Medicine, Baltimore, Maryland 21228
}

\begin{abstract}
Transient changes in the activity of midbrain dopamine neurons encode an error signal that contributes to associative learning. Although considerable attention has been devoted to the mechanisms contributing to phasic increases in dopamine activity, less is known about the origin of the transient cessation in firing accompanying the unexpected loss of a predicted reward. Recent studies suggesting that the lateral habenula $(\mathrm{LHb})$ may contribute to this type of signaling in humans prompted us to evaluate the effects of LHb stimulation on the activity of dopamine and non-dopamine neurons of the anesthetized rat. Single-pulse stimulation of the LHb $(0.5 \mathrm{~mA}, 100 \mu \mathrm{s})$ transiently suppressed the activity of $97 \%$ of the dopamine neurons recorded in the substantia nigra and ventral tegmental area. The duration of the cessation averaged $\sim 85 \mathrm{~ms}$ and did not differ between the two regions. Identical stimuli transiently excited $52 \%$ of the non-dopamine neurons in the ventral midbrain. Electrolytic lesions of the fasciculus retroflexus blocked the effects of LHb stimulation on dopamine neurons. Local application of bicuculline but not the SK-channel blocker apamin attenuated the effects of LHb stimulation on dopamine cells, indicating that the response is mediated by $\mathrm{GABA}_{\mathrm{A}}$ receptors. These data suggest that $\mathrm{LHb}$-induced suppression of dopamine cell activity is mediated indirectly by orthodromic activation of putative GABAergic neurons in the ventral midbrain. The habenulomesencephalic pathway, which is capable of transiently suppressing the activity of dopamine neurons at a population level, may represent an important component of the circuitry involved in encoding reward expectancy.
\end{abstract}

Key words: associative learning; apamin; bicuculline; GABAergic; habenula; substantia nigra; ventral tegmental area

\section{Introduction}

Transient changes in the spontaneous firing of dopamine (DA) neurons in the substantia nigra (SN) and ventral tegmental area (VTA) occur in response to a variety of salient environmental cues (Miller et al., 1981; Freeman et al., 1985; Horvitz et al., 1997). Novel stimuli with appetitive value (e.g., unexpected rewards) elicit phasic increases in DA cell firing that are indistinguishable from those triggered by neutral sensory stimuli that predict the occurrence of these events (i.e., conditioned stimuli) (Ljungberg et al., 1992; Schultz et al., 1993; Pan et al., 2005). In contrast, unexpected omission of an anticipated reward results in a transient cessation in neuronal activity (Ljungberg et al., 1992; Schultz et al., 1993; Tobler et al., 2003; Pan et al., 2005). These findings have led to the proposition that DA neurons encode an error signal that reports the fidelity of ongoing events relative to a previous prediction (Schultz et al., 1997; Fiorillo et al., 2003; Satoh et al., 2003; Nakahara et al., 2004; Morris et al., 2006).

Excitatory inputs from the pedunculopontine nucleus contribute to the phasic increase in DA cell firing evoked by salient environmental stimuli (Pan and Hyland, 2005). Glutamatergic projections from the prefrontal cortex and subthalamic nucleus

Received March 2, 2007; revised May 10, 2007; accepted May 24, 2007.

This work was supported by United States Public Health Service Grant MH-072647. We thank J. Gold, H. Holcomb, P. O'Donnell, and N. Mosha for their insights and helpful comments on this manuscript.

Correspondence should be addressed to Dr. Paul D. Shepard, Maryland Psychiatric Research Center, P.0. Box 21247, Baltimore, MD 21228. E-mail: pshepard@mprc.umaryland.edu.

DOI:10.1523/JNEUROSCI.0958-07.2007

Copyright $\odot 2007$ Society for Neuroscience $\quad$ 0270-6474/07/276923-08\$15.00/0 also increase bursting activity and could be involved in eliciting transient increases in DA cell firing (Gariano and Groves, 1988; Smith and Grace, 1992). The origin of the pathway(s) responsible for the cessation in DA cell activity observed in response to the absence of a predicted reward has yet to be established. However, recent brain imaging studies have suggested that the habenular complex may be involved. Using functional magnetic resonance imaging to investigate brain activity in human subjects performing a prediction task, Ullsperger and von Cramon (2003) found that negative feedback led to greater hemodynamic responses in the habenula than either correct responses with positive feedback or incorrect responses with no feedback. Habenular activity was also increased in trials when correct responses were followed by neutral (i.e., noninformative) feedback.

Although not as well characterized as other inputs to midbrain and hindbrain monoaminergic neurons, cells in the lateral habenula ( $\mathrm{LHb}$ ) project to the SN, VTA, and raphe nuclei (Bunney and Aghajanian, 1976; Herkenham and Nauta, 1979; Ferraro et al., 1996; Lecourtier and Kelly, 2007). Biochemical and electrophysiological studies indicate that the habenulomesencephalic pathway is capable of altering the activity of DA-containing neurons at a population level. Lesions of the habenula or blockade of impulse traffic in the fasciculus retroflexus increases DA release in the forebrain (Lisoprawski et al., 1980; Nishikawa et al., 1986). LHb stimulation inhibits the majority of spontaneously firing DA-containing neurons in the substantia nigra pars compacta (SNc) and VTA (Christoph et al., 1986) as well as a large percentage of neurons in the dorsal raphe (Wang and Aghajanian, 1977). 
Although the inhibitory effects of LHb stimulation on serotonergic neurons have been attributed to activation of GABAcontaining interneurons (Ferraro et al., 1996), the mechanism responsible for the inhibition of DA cell activity has yet to be established. In the present series of experiments, we sought to confirm the ability of LHb stimulation to inhibit DA neuronal firing and to explore the mechanism underlying these effects.

\section{Materials and Methods}

Surgical procedures. All experiments were performed using adult, male Sprague Dawley rats (260-440 g; Charles River Laboratories, Wilmington, MA). Animals were housed in a temperature-controlled vivarium under scheduled lighting conditions ( $12 \mathrm{~h}$ light/dark cycle) and provided unrestricted access to food and water. All experiments were conducted in strict accordance with the procedures described in the Guide for the Care and Use of Laboratory Animals adopted by the National Institutes of Health and the University of Maryland School of Medicine.

Rats were anesthetized with chloral hydrate $(400 \mathrm{mg} / \mathrm{kg}$, i.p.), and the femoral vein was cannulated for intravenous administration of supplementary anesthetic. Tissues surrounding the ear canals and wound margins were infiltrated with $2 \%$ mepivacaine before positioning the animal in a stereotaxic frame (David Kopf Instruments, Tujunga, CA). Body temperature was maintained at $37^{\circ} \mathrm{C}$ using a feedback-controlled heating pad. The scalp was incised, and two burr holes were drilled in the skull overlying the ventral midbrain to permit insertion of recording and stimulating electrodes, respectively. In some experiments, a third hole was drilled in the skull in the region of the caudal diencephalon $(3.8 \mathrm{~mm}$ posterior to bregma, $0.7 \mathrm{~mm}$ lateral to midline, $6.8 \mathrm{~mm}$ ventral to pial surface) to lesion the fasciculus retroflexus.

Single-unit recording. Recording electrodes were prepared from borosilicate glass capillary tubing ( $1.5 \mathrm{~mm}$ outer diameter; World Precision Instruments, Sarasota, FL) using a vertical puller (PE-2; Narishige, Tokyo, Japan) and filled with one of the following solutions: $0.5 \mathrm{M} \mathrm{NaCl}, 0.5$ $\mathrm{M} \mathrm{NaCl}$ plus $20 \mathrm{~mm}$ bicuculline methiodide or $0.5 \mathrm{M}$ saline plus $125 \mu \mathrm{M}$ apamin. Tips were broken back to achieve a final impedance of $4-6 \mathrm{M} \Omega$ in vitro $(\sim 2-4 \mu \mathrm{m}$ diameter $)$. Recording electrodes were attached to a piezoelectric microdrive (Inchworm; Burleigh, Mississauga, Ontario, Canada) and positioned in the region of the VTA $(4.8-5.3 \mathrm{~mm}$ posterior from bregma, $0.5-0.9 \mathrm{~mm}$ lateral to the midline, $7.5-8.3 \mathrm{~mm}$ ventral to pial surface) or SN (4.8-5.3 mm posterior from bregma, $1.2-2.5 \mathrm{~mm}$ lateral to the midline, $7.6-8.5 \mathrm{~mm}$ ventral to pial surface). Recordings obtained from cells in the VTA were confined to intermediate and lateral parts of the parabrachial pigmentosus and paranigral regions and did not include medial structures such as the interfascicular or caudal linear nuclei. A stainless steel pin implanted in the neck musculature served as the electrical ground. Electrodes were slowly advanced $\left(1-2 \mu \mathrm{m} \mathrm{s}^{-1}\right)$ until a spontaneously active cell could be isolated from background noise. Recording electrodes were replaced periodically in response to an abrupt change in the signal-to-noise ratio. Electrode potentials were amplified, filtered ( $0.1-8 \mathrm{kHz}$ bandpass), and monitored in real time using a digital oscilloscope and audiomonitor. Electrical activity immediately preceding and following stimulation of the $\mathrm{LHb}$ was digitized at $10 \mathrm{kHz}$ using a 16-bit laboratory interface (Digidata 1321A; Molecular Devices, Union City, CA) and stored on disk for off-line analysis. Individual spikes were isolated from background noise using a window discriminator, the output of which was directed to personal computer-based data acquisition system (RISIPS; Symbolic Logic, Dallas, TX) that displayed firing rate data while simultaneously capturing interspike interval and stimulus occurrence data for analysis off-line. Recordings and surgery were completed on the same day.

At the conclusion of each experiment, methylene blue dye was deposited by current injection $(-20 \mu \mathrm{A}, 40 \mathrm{~min})$ to mark the final position of the recording electrode. Rats were deeply anesthetized with chloral hydrate and perfused transcardially with saline, followed by $10 \%$ neutral buffered formalin. The brain was removed, sectioned on a cryostat (50 $\mu \mathrm{m}$ ), and examined microscopically. Because several neurons were recorded in each animal, it was not possible to determine the precise location of each cell studied. The relative position of these cells was estimated from the trajectory of electrode tracts visualized in adjacent tissue sections. Cells recorded in tracts positioned $\leq 1 \mathrm{~mm}$ from the midline were assigned to the VTA group, whereas those located more laterally were operationally defined as SN neurons.

Individual units were identified as DA neurons on the basis of their well established electrophysiological characteristics including longduration $(3.2 \pm 0.04 \mathrm{~ms} ; n=42)$ triphasic action potentials, slow firing rates $(4.3 \pm 0.1 ; n=103)$, and an irregular single-spike or burst firing discharge pattern (Bunney et al., 1973; Wang, 1981; Grace and Bunney, 1983). All non-DA-containing cells selected for study exhibited comparatively fast firing rates $(11.4 \pm 1.2 \mathrm{~Hz} ; n=50)$ and short-duration biphasic action potentials $(2.0 \pm 0.04 ; n=99)$ that, when audiomonitored, gave rise to a higher pitched sound that could easily be distinguished from that associated with DA neurons. In accordance with previous studies, cells possessing these characteristics were considered to be putative GABA-containing neurons (Guyenet and Aghajanian, 1978; Waszczak et al., 1984; Richards et al., 1997; Steffensen et al., 1998; Gernert et al., 2004).

Drug administration. The selective $\mathrm{GABA}_{\mathrm{A}}$ receptor antagonist bicuculline methiodide and the selective SK-channel blocker apamin (Sigma, St. Louis, MO) were applied locally to DA neurons via passive diffusion from the recording electrode (Steward et al., 1990; Tepper et al., 1995). Cells were isolated and observed for $5 \mathrm{~min}$ before the onset of recording. The firing rate and discharge pattern of cells studied using drug-filled electrodes in the absence of $\mathrm{LHb}$ stimulation did not change during the experiment, indicating that drug effects were both rapid in onset and stable over time.

Stimulation and electrolytic lesions. Epoxylite-coated, concentric bipolar stimulating electrodes were obtained from commercial sources (SNE100; Rhodes Medical Instruments, Summerland, CA). Constant current stimuli consisted of single, monophasic, rectangular pulses of fixed duration $(100 \mu \mathrm{s})$ and intensity $(0.5 \mathrm{~mA})$. Stimulus pulses were generated using a digital stimulator (PG4000; Neuro Data Instruments, New York, NY), passed to a constant current stimulus isolator (A-365; World Precision Instruments), and delivered at a frequency of $0.5 \mathrm{~Hz}$.

In some experiments, stimulating electrodes were used to lesion the fasciculus retroflexus $1 \mathrm{~h}$ before the start of the recording studies. Unilateral lesions were made by applying $0.35 \mathrm{~mA}$ of anodal direct current for $8 \mathrm{~s}$ and were made ipsilateral to the planned recording site. The position of the stimulating electrode and location and specificity of the lesion were confirmed histologically in $50-\mu \mathrm{m}$-thick sections stained with cresyl violet (see Fig. 2).

Data analysis. Well isolated neurons (one to eight per rat) were recorded for 2-3 min to establish their baseline firing properties. In addition to firing rate (all cells), spike trains from DA neurons were analyzed for evidence of bursting activity using the criteria developed and validated by Grace and Bunney (1984). Briefly, burst starts were identified as spike pairs with an interspike interval $\leq 80 \mathrm{~ms}$, and all subsequent spikes were considered part of that burst until an interval exceeding $160 \mathrm{~ms}$ was encountered, which signaled its termination. Although spike doublets were counted as bursts, neurons had to exhibit a minimum of three three-spike bursts to be classified as burst firing. The percentage of spikes discharged in bursts as well as the proportion of long (three or more spikes) and short (two spikes) bursts was determined for each cell that satisfied the operational definition of bursting activity.

After determining the basal firing properties, each cell was tested for its response to single-pulse stimulation of the LHb. Peristimulus time histograms were compiled from 100 stimulus presentations and displayed using a $1 \mathrm{~ms}$ binwidth. Latency to onset, duration, and magnitude of stimulus-evoked changes in neuronal activity were determined from CUMSUM plots constructed by adding the contents of each individual bin to a running sum of all previous events (Davey et al., 1986; Tepper et al., 1995). Control activity was determined from the slope of a leastsquares regression line fit to $100 \mathrm{~ms}$ of prestimulus data. Stimulusinduced changes in firing probability were determined by comparing the slope of discrete regions of each CUMSUM plot with control values (see example in Fig. 1). A change in firing probability was defined as an increase or decrease in slope exceeding $30 \%$ of control. The latency to onset and duration of the various components of the response to LHb 
A

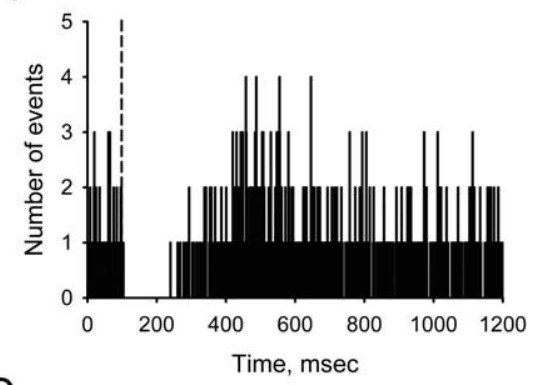

C

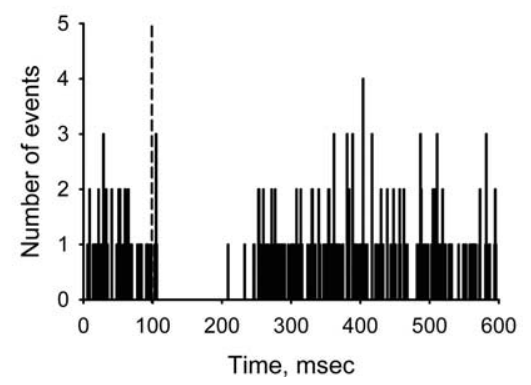

B

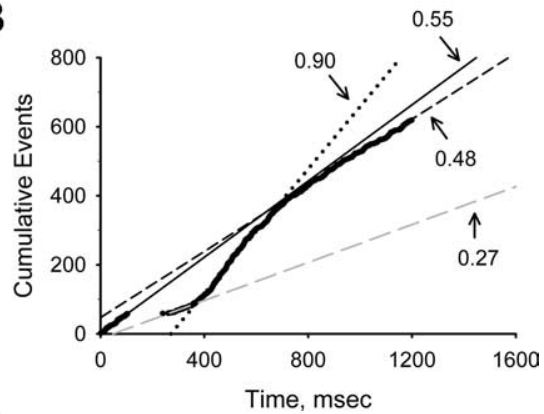

D

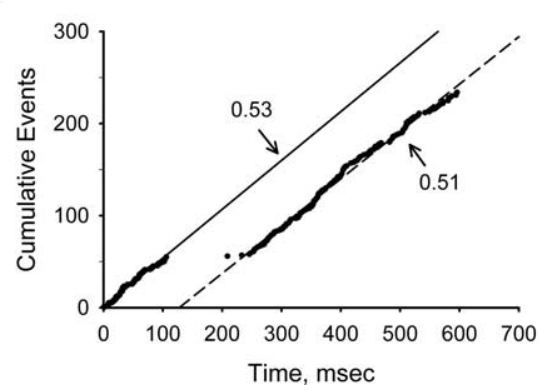

Figure 1. Representative effects of $\mathrm{LHb}$ stimulation on the spontaneous activity of midbrain DA neurons. $\boldsymbol{A}, \boldsymbol{C}$, Peristimulus time histograms comprising 100 consecutive sweeps. Stimuli consisted of rectangular current pulses $(0.5 \mathrm{~mA}, 100 \mu \mathrm{s})$ delivered $100 \mathrm{~ms}$ after the start of each sweep (vertical dashed line). $\boldsymbol{B}, \boldsymbol{D}$, CUMSUM plots of the data illustrated in $\boldsymbol{A}$ and $\boldsymbol{C}$, respectively. Graphs were generated by adding the contents of consecutive bins in the corresponding peristimulus time histogram to create a cumulative total of the number of spikes recorded across trials. Decimal values denote the slope of a line fit to each component of the response by least-squares regression (solid line, control; long dash, inhibition; dotted line, delayed excitation; short dash, recovery). $\boldsymbol{A}, \boldsymbol{B}$, Biphasic response. In these cells, typical of $66 \%$ of the DA neurons recorded, $\mathrm{LHb}$ stimulation resulted in a cessation in spontaneous firing, followed by a delayed excitation. $C, D$, Inhibitory response. In $\sim 33 \%$ of the cells studied, stimulation suppressed DA cell firing without inducing a delayed excitation.

stimulation was determined from the intersection of adjacent regression lines on CUMSUM plots.

Unless indicated otherwise, all data are expressed as mean \pm SE. Omnibus testing was conducted using a Student's $t$ test or one-way ANOVA unless the underlying assumptions of normality and equal variance were violated, in which case the Kruskal-Wallis one-way ANOVA on ranks was substituted. Post hoc comparisons were made using a Bonferroni $t$ test (parametric) or Dunn's method (nonparametric). All post hoc comparisons were two sided at $\alpha=0.05$.

\section{Results}

The results of the present study are based on recordings obtained from 202 spontaneously active neurons in the ventral midbrain including 103 cells identified as dopaminergic on the basis of their firing properties. Because several cells were often studied in each animal, it was not possible to verify the location of every neuron recorded. However, based on the position of electrode tracts and dye spots recovered from final electrode placements, it was inferred that $\sim 70 \%$ of the DA neurons studied were located within the mediolateral region of the $\mathrm{SN}$, with the remainder distributed in the VTA. An additional 99 non-DA neurons located in both the SN and VTA exhibited firing properties typical of those attributed to putative GABA-containing neurons (Guyenet and Aghajanian, 1978; Waszczak et al., 1984; Richards et al., 1997; Steffensen et al., 1998; Gernert et al., 2004). Because there are no definitive anatomical boundaries between the $\mathrm{SN}$ and VTA, we cannot exclude the possibility that some of the neurons included in the latter group actually resided in the medial regions of the SN.

\section{Effects of LHb stimulation on the spontaneous activity of nigral and VTA DA neurons}

Single-pulse stimulation of the LHb resulted in a brief but complete suppression of the spontaneous firing of $97 \%$ of the DA neurons sampled in the SN (69 of 71) and VTA (31 of 32). Peristimulus histograms and CUMSUM plots illustrating the typical response of these cells to a $0.5 \mathrm{~mA}$ current pulse are illustrated in Figure 1. The majority of DA cells in the SN (51 of 71) and approximately half of the cells in the VTA (15 of 32) exhibited a biphasic response comprising an initial suppression in firing followed by delayed excitation $(-/+)$, whereas the remaining neurons showed a unilateral inhibition $(-)$. The duration of the cessation in activity averaged $84.5 \pm 4.2 \mathrm{~ms}$ (range, $14-205 \mathrm{~ms} ; n=$ $100)$ and did not differ between cells in the SN and VTA $(86.4 \pm 5.2$ and $80.4 \pm 7.0$ $\mathrm{ms}$, respectively) or by response type $(-/+: 86.6 \pm 4.9 \mathrm{~ms}, n=66 ;-: 80.5 \pm 7.9$ ms, $n=34)$. Latency to onset of the suppression in firing was brief $(5.8 \pm 0.4 \mathrm{~ms})$ and followed by an interval of reduced spiking probability that increased the overall duration of the inhibition to $120.8 \pm 6.0 \mathrm{~ms}$. When present, the delayed excitation persisted for an average of $154 \pm 11 \mathrm{~ms}$ and resulted in a $116 \pm 10 \%$ increase in CUMSUM slope relative to the prestimulus control period. Of 103 DA neurons studied, one neuron failed to respond to LHb stimulation, and two others were excited.

\section{Electrolytic lesions of the fasciculus retroflexus}

In an effort to establish the specificity of the response of DA neurons to LHb stimulation, unilateral electrolytic lesions of the fasciculus retroflexus were made in 10 rats, $1 \mathrm{~h}$ before the start of the recording studies. Lesions were made caudal to the site of stimulation to avoid damaging the $\mathrm{LHb}$ and adjacent structures (Fig. 2 B). Of the 43 DA neurons in the VTA and $\mathrm{SNc}$ recorded in these animals, $77 \%(n=33)$ failed to respond to ipsilateral stimulation of the LHb, whereas the remainder were either inhibited $(n=7)$ or showed evidence of a unilateral excitation $(n=3)$ (Table 1). Three cells recorded in lesioned animals exhibited a cessation in firing, although the duration of the response (25.7 \pm $3.8 \mathrm{~ms}$ ) was shorter than that observed in unlesioned animals $(84.5 \pm 4.2 \mathrm{~ms} ; n=100)$. No differences were observed between the basal firing rates of DA neurons recorded in lesioned and unlesioned animals (Table 1).

\section{Effects of LHb stimulation on the spontaneous activity of nigral and VTA non-DA neurons}

Non-DA neurons in the ventral midbrain exhibited a more variable response to $\mathrm{LHb}$ stimulation than their DA counterparts. Neuronal responses fell into four general categories based on the initial response to stimulation (Fig. 3, Table 2). Single stimulus pulses, identical to those used to inhibit DA neurons $(0.5 \mathrm{~mA}, 100$ $\mu$ s duration, $0.5 \mathrm{~Hz}$ ), excited $52.5 \%$ of non-DA cells in the SN and VTA. Approximately half of these neurons (24 of 52) exhib- 


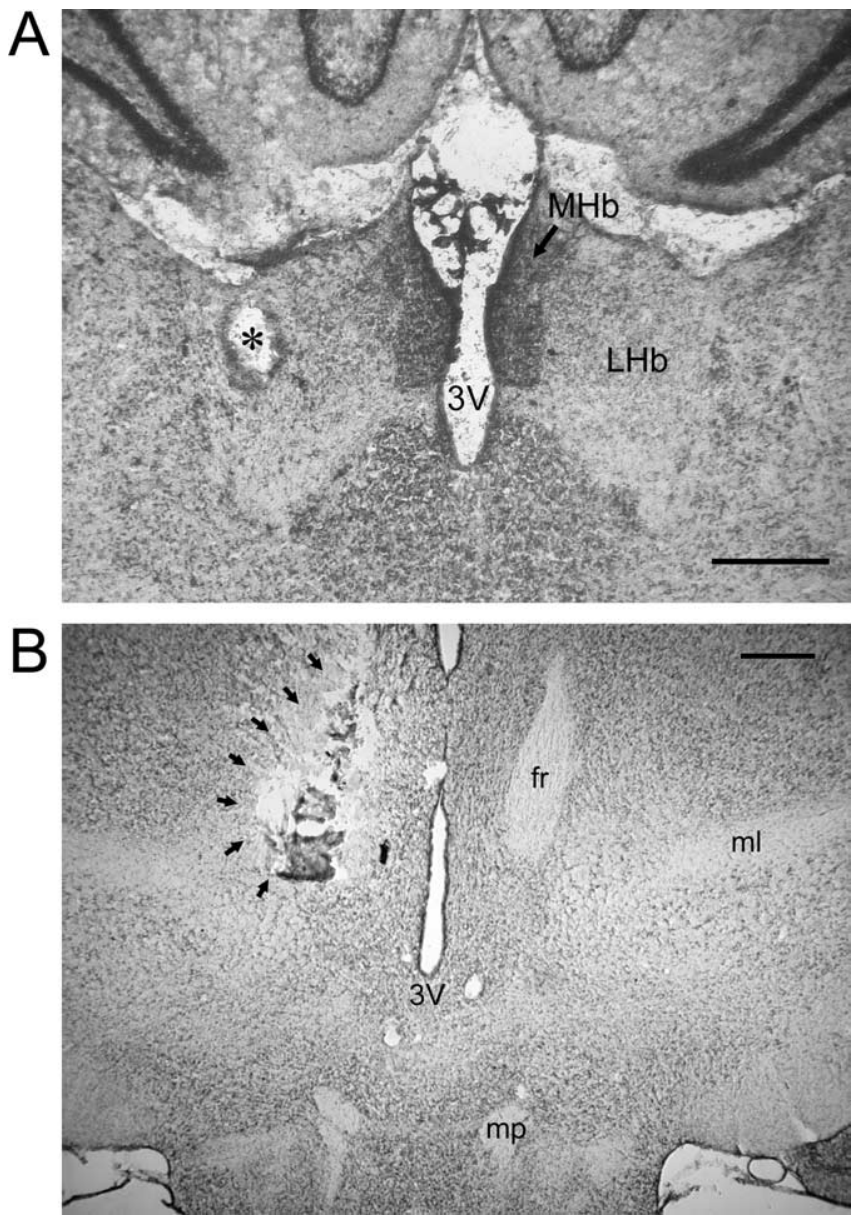

Figure 2. $\boldsymbol{A}, \boldsymbol{B}$, Photomicrographs illustrating placement of the stimulating electrode in the $\mathrm{LHb}(\boldsymbol{A})$ and tissue damage resulting from electrolytic lesion of the fasciculus retroflexus $(\boldsymbol{B})$. The asterisk in $\boldsymbol{A}$ denotes the position of the tip of the stimulating electrode. The arrows in $\boldsymbol{B}$ outline the perimeter of a unilateral electrolytic lesion of the fasciculus retroflexus. MHb, Medial habenula; 3V, third ventricle; fr, fasciculus retroflexus; ml, medial leminscicus; mp, mammillary peduncle. Scale bars, $0.5 \mathrm{~mm}$.

ited a short latency burst of activity that was consistently followed by a transient cessation in activity or an interval of reduced spiking (Fig. 3A). Variations in response latency (Fig. $3 A$, inset), together with the failure of spontaneous action potentials to collide with stimulus-elicited spikes, indicated that the excitation was the result of a fast orthodromic as opposed to an antidromic response. The remaining 28 cells excited by LHb stimulation exhibited responses that were both longer in duration and latency relative to the stimulus onset (Fig. $3 B$, Table 2). Approximately two-thirds of these cells showed a subsequent inhibition in activity. An additional 22 cells were inhibited by LHb stimulation (Fig. $3 C$ ). The duration and latency of the inhibitory effects were comparable to cells exhibiting the slower of the two excitatory responses. The remaining neurons showed no measurable response to LHb stimulation (Fig. 3D). Cells in each of the four response categories exhibited similar spontaneous firing rates (Table 1).

\section{Effects of apamin and bicuculline on the response of DA neurons to $\mathrm{LHb}$ stimulation}

To evaluate the contribution made by $\mathrm{GABA}_{\mathrm{A}}$ receptors to the cessation in DA cell firing, we compared the effects of LHb stimulation between groups of neurons recorded using conventional saline-filled electrodes and electrodes filled with saline plus bicu- culline (20 mM). Five to eight neurons were studied in each animal. Typically, three to five recordings were made using control electrodes before switching to bicuculline-filled pipettes. To control for the pore-blocking effects of bicuculline on SK-type $\mathrm{Ca}^{2+}$. activated $\mathrm{K}^{+}$channels (Seutin et al., 1997; Khawaled et al., 1999), a series of recordings were also made using electrodes containing $125 \mu \mathrm{M}$ apamin, a selective SK-channel blocker (Hugues et al., 1982; Bond et al., 2005). Data obtained using electrodes containing bicuculline $(n=45)$ were compared with a control group $(n=39)$ comprising recordings obtained from animals using saline-filled electrodes. All of the DA neurons recorded using bicuculline-filled electrodes exhibited sustained bursting activity. As a group, bicuculline-treated neurons exhibited faster firing rates $(5.6 \pm 0.2 \mathrm{~Hz} ; n=45)$ than cells recorded using saline-filled pipettes $\left(4.4 \pm 0.1 \mathrm{~Hz} ; n=39 ; t_{(82)}=-1.2 ; p<0.001\right)$, differences that persisted when the control group was limited to cells with a spontaneous bursting discharge $(4.6 \pm 0.2 ; n=27)$. Bicuculline significantly increased the percentage of spikes discharged in bursts (control: $31.7 \pm 4.4 \%, n=27$; bicuculline: $75.8 \pm 2.1 \%$, $\left.n=45 ; t_{(70)}=-44.1 ; p<0.001\right)$. Natural bursts recorded using control electrodes were composed of a higher proportion of twospike events $(53.1 \pm 3.9 \% ; n=27)$ and a lower proportion of longer bursts (three or more spikes; $46.9 \pm 3.9 \% ; n=27$ ) than bursting activity exhibited by bicuculline-treated cells (two spikes: $17.5 \pm 1.7, t_{(70)}=35.6, p<0.001$; three or more spikes: $\left.82.6 \pm 1.7 \%, t_{(70)}=-9.5, p<0.001, n=45\right)$.

Bicuculline, but not apamin, significantly changed the response of DA neurons to LHb stimulation $\left(\chi^{2}=43.4 ; \mathrm{df}=6 ; p<\right.$ $0.001)$. Whereas $93 \%$ of the DA neurons recorded using apamincontaining electrodes were inhibited by LHb stimulation, $58 \%$ of the cells recorded using bicuculline-filled electrodes exhibited evidence of an inhibitory response. As illustrated in Figure 4A, bicuculline reduced the proportion of cells showing a biphasic response $(-/+)$ while increasing the number of neurons that were excited by LHb stimulation. The number of nonresponsive cells was also increased. Of the bicuculline-treated DA cells that continued to be inhibited by LHb stimulation, both the duration of the inhibition (control: $118.3 \pm 6.5 \mathrm{~ms}, n=69$; bicuculline: $79.5 \pm 12.8 \mathrm{~ms}, n=26$ ) and the cessation in spontaneous firing (control: $86.4 \pm 5.2 \mathrm{~ms}, n=69$; bicuculline: $31.3 \pm 4.2 \mathrm{~ms}, n=$ 22) were significantly reduced (Fig. $4 B$ ). In four bicucullinetreated cells, inhibitory responses were not sufficient to cause a cessation in firing, an effect that was never observed in control or apamin-treated neurons. Neither the duration nor the magnitude of the delayed excitation was altered by bicuculline, although the latency to onset was reduced $(173.8 \pm 13.1 \mathrm{~ms} ; n=$ 26) compared with both control $(242.0 \pm 8.0 \mathrm{~ms} ; n=53)$ and apamin-treated $(297.2 \pm 21.0 ; n=21)$ cells. Although local application of apamin did not alter the inhibitory effects of LHb stimulation on DA neurons, the duration of the excitatory component of the biphasic response (control: $156.9 \pm 13.0 \mathrm{~ms}, n=$ 53; apamin: $219.9 \pm 22.8 \mathrm{~ms}, n=21$ ) was increased.

\section{Discussion}

The existence of a projection from the LHb to the ventral midbrain has been firmly established (Bunney and Aghajanian, 1976; Herkenham and Nauta, 1979; Phillipson, 1979). Despite a growing body of information regarding the cytochemical and morphological features of the LHb (Emson et al., 1977; Cuello et al., 1978; Vincent et al., 1980; Andres et al., 1999; Geisler et al., 2003) and evidence implicating the habenulomesencephalic pathway in DA-related behaviors and disorders (Ullsperger and von Cramon, 2003; Shepard et al., 2006), only one previous electro- 
Table 1. Effects of fasciculus retroflexus lesions on the response of DA neurons to stimulation of the LHb

\begin{tabular}{|c|c|c|c|c|c|c|}
\hline \multirow[b]{2}{*}{ Response type } & \multicolumn{3}{|c|}{ Control ( $n=103$ cells) } & \multicolumn{3}{|c|}{ Lesioned ( $n=43$ cells) } \\
\hline & $n(\%)$ & Basal rate $(\mathrm{Hz})$ & $\begin{array}{l}\text { Cessation duration } \\
(\mathrm{ms})(n)\end{array}$ & $n(\%)$ & Basal rate $(\mathrm{Hz})$ & $\begin{array}{l}\text { Cessation duration } \\
(\mathrm{ms})(n)\end{array}$ \\
\hline Cessation & $34(33)$ & $4.3 \pm 0.6$ & $80.5 \pm 7.9(34)$ & $5(11.6)$ & $4.8 \pm 0.3$ & $25.7 \pm 3.8(3)$ \\
\hline Cessation/+ & $66(64)$ & $4.4 \pm 0.3$ & $86.6 \pm 4.9(66)$ & $2(4.7)$ & $4.8 \pm 0.3$ & \\
\hline Excitation only & $2(2)$ & & NA & $3(7.0)$ & $3.5 \pm 1.1$ & NA \\
\hline No response & $1(1)$ & & NA & $33(76.7)$ & $4.2 \pm 0.3$ & NA \\
\hline
\end{tabular}

NA, Not applicable.
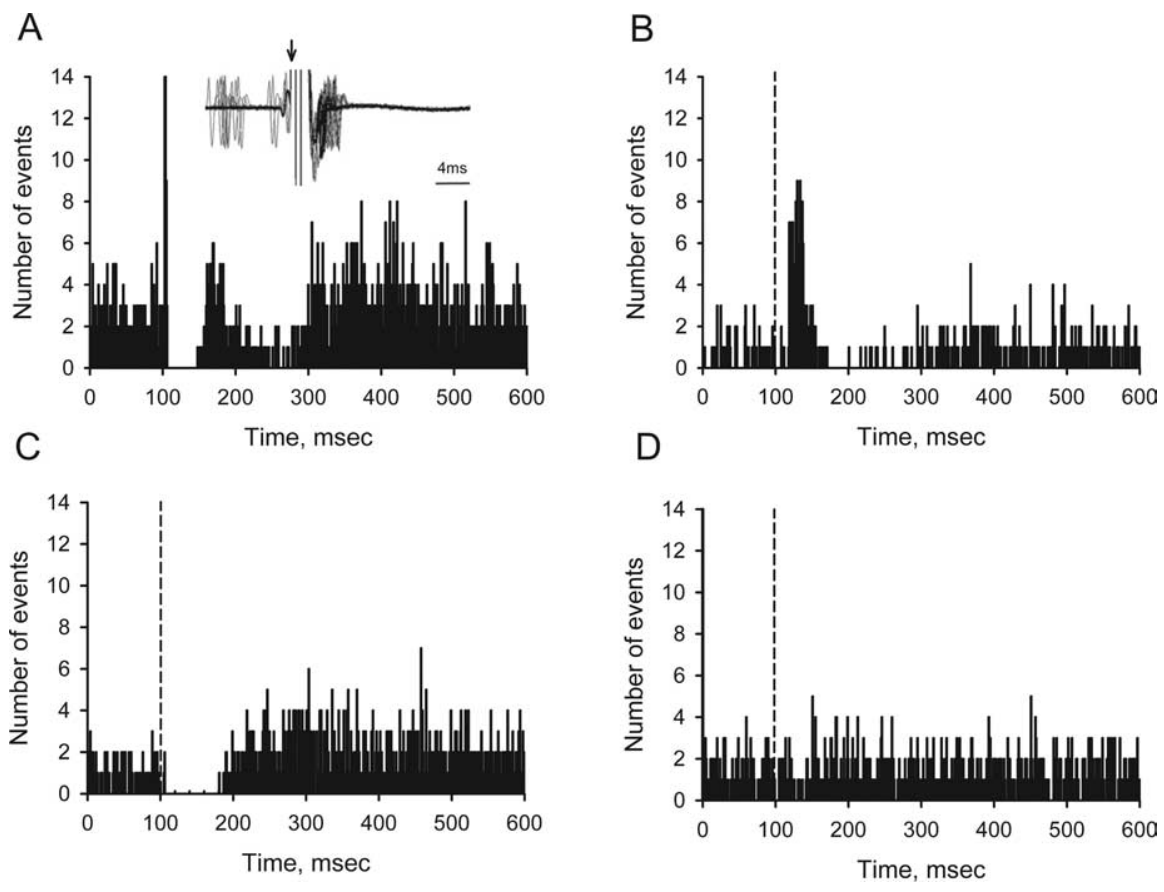

Figure 3. Representative peristimulus time histograms illustrating the four main types of responses displayed by non-DA neurons in the SN and VTA after single-pulse stimulation $(0.5 \mathrm{~mA}, 100 \mu \mathrm{s})$ of the LHb. A, Fast excitation/inhibition. Although spikes were often observed in close proximity to the stimulus artifact (inset), there was no evidence of collision with action potentials discharged spontaneously before stimulus onset. $\boldsymbol{B}$, Excitation or excitation/inhibition. Note the slower onset of the initial excitation. $\boldsymbol{C}$, Inhibition or inhibition/excitation. $\boldsymbol{D}$, No response. Peristimulus time histograms were compiled from 100 consecutive sweeps and displayed using a binwidth of $1 \mathrm{~ms}$. The vertical dashed line denotes stimulus onset in all panels except $\boldsymbol{A}$, in which a short-latency excitation, commensurate with the stimulus onset, is observed.

Table 2. Effects of LHb stimulation on the spontaneous activity on non-DA neurons in the ventral midbrain

\begin{tabular}{|c|c|c|c|c|c|c|}
\hline \multirow[b]{2}{*}{ Initial response } & \multirow[b]{2}{*}{ Secondary response } & \multirow[b]{2}{*}{$n(\%)$} & \multirow[b]{2}{*}{$\begin{array}{l}\text { Firing rate } \\
(\mathrm{Hz})\end{array}$} & \multicolumn{2}{|c|}{ Initial response } & \multirow{2}{*}{$\begin{array}{l}\begin{array}{l}\text { Secondary } \\
\text { response }\end{array} \\
\begin{array}{l}\text { Duration } \\
\text { (ms) }\end{array}\end{array}$} \\
\hline & & & & $\begin{array}{l}\text { Latency } \\
\text { (ms) }\end{array}$ & $\begin{array}{l}\text { Duration } \\
\text { (ms) }\end{array}$ & \\
\hline Fast excitation & Inhibition & 24 & $15.4 \pm 4.4$ & $3.2 \pm 0.2$ & $5.1 \pm 1.0$ & $43.3 \pm 4.6$ \\
\hline Excitation & & 28 & $9.2 \pm 1.2$ & $18.7 \pm 2.2$ & $26.3 \pm 4.5$ & \\
\hline Excitation & None & 10 & & $22.8 \pm 5.2$ & $34.6 \pm 10.8$ & \\
\hline Excitation & Inhibition & 18 & & $16.4 \pm 1.7$ & $21.6 \pm 3.3$ & $79.5 \pm 12.1$ \\
\hline Inhibition & & 22 & $12.0 \pm 2.9$ & $12.5 \pm 2.2$ & $37.1 \pm 5.3$ & \\
\hline Inhibition & None & 13 & & $14.0 \pm 3.2$ & $40.6 \pm 6.5$ & \\
\hline Inhibition & Excitation & 9 & & $10.4 \pm 3.0$ & $32.0 \pm 9.3$ & $36.1 \pm 6.5$ \\
\hline No response & & 25 & $12.9 \pm 2.2$ & & & \\
\hline Total & & 99 & & & & \\
\hline
\end{tabular}

physiological study has attempted to explore the functional relationship between the LHb and DA neurons in the SN and VTA. Using single-unit recording techniques in anesthetized rats, Christoph et al. (1986) found that stimulation of the lateral but not the medial habenula powerfully suppressed the activity of DA neurons in the SN and VTA. The present results have confirmed these findings with a striking degree of fidelity. As reported previously, the majority of DA neurons $(\sim 97 \%)$ were temporarily silenced by single-pulse stimulation of the LHb. Initial inhibitory effects were often followed by a delayed excitation, although the opposite was never observed. SN and VTA DA neurons were equally responsive to LHb stimulation aside from a slight increase in the proportion of $\mathrm{SN}$ neurons showing a biphasic $(-/+)$ response.

The consistency of the effect (almost exclusively inhibitory), its magnitude (often a complete cessation of spontaneous firing), and scope (nearly all DA neurons in the SN and VTA affected) belies the extent of the innervation of the ventral midbrain by LHb efferents. To determine whether current spread to adjacent structures contributed to our results, we took advantage of the highly circumscribed nature of the fasciculus retroflexus, a fiber bundle that conveys habenular efferents to the midbrain. By lesioning the pathway at mid-diencephalic levels, we avoided damaging the LHb and contiguous brain structures. Unilateral lesions blocked the inhibitory and excitatory effects of LHb stimulation in the majority (77\%) of cells tested. Partial lesions, particularly those that left the outer margins of the pathway intact, were less effective than lesions that destroyed the entire tract. Comparable results were reported by Christoph et al. (1986), who also found that axon-sparing lesions of the LHb blocked the effects of LHb stimulation on DA neurons. The small number of neurons that continued to respond after fasciculus retroflexus lesions is consistent with reports that the pathway is crossed (Herkenham and Nauta, 1979).

Results showing that local application of bicuculline block or attenuate LHbinduced inhibition of DA neurons indicate that this component of the response is mediated by $\mathrm{GABA}_{\mathrm{A}}$ receptors. Bicuculline was delivered to the vicinity of the cell by adding it to the recording electrode, an approach that has been used successfully by others (Tepper et al., 1995). Because it is doubtful that bicuculline would have diffused very far from the recording site, its effects were likely attributable to blockade of $\mathrm{GABA}_{\mathrm{A}}$ receptors on the DA neuron being recorded. In support of this notion, cells studied using bicuculline-containing electrodes exhibited significantly faster firing rates and a higher incidence of bursting activity than DA neurons recorded using saline-filled electrodes. $\mathrm{GABA}_{\mathrm{A}}$ receptors are located on both DA and non-DA cells in the SN and VTA (Guyenet and Aghajanian, 1978; Grace and Bunney, 


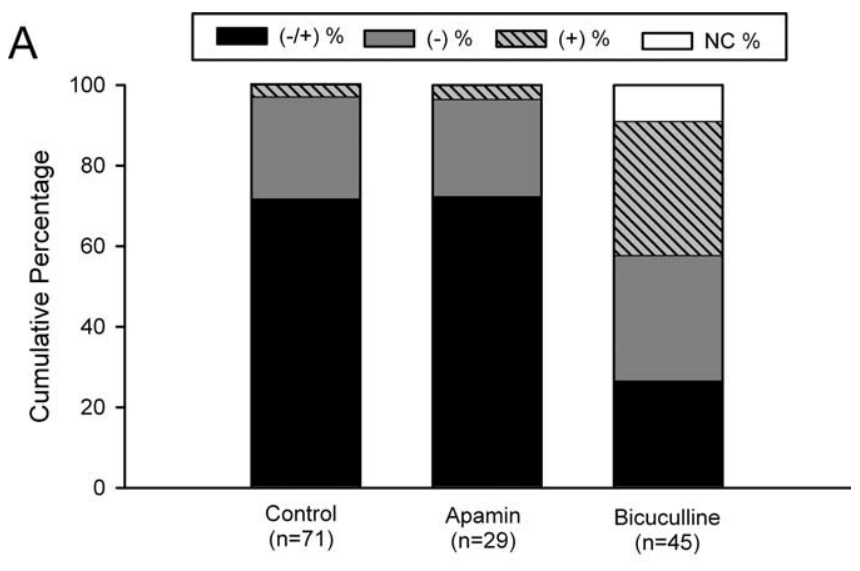

B

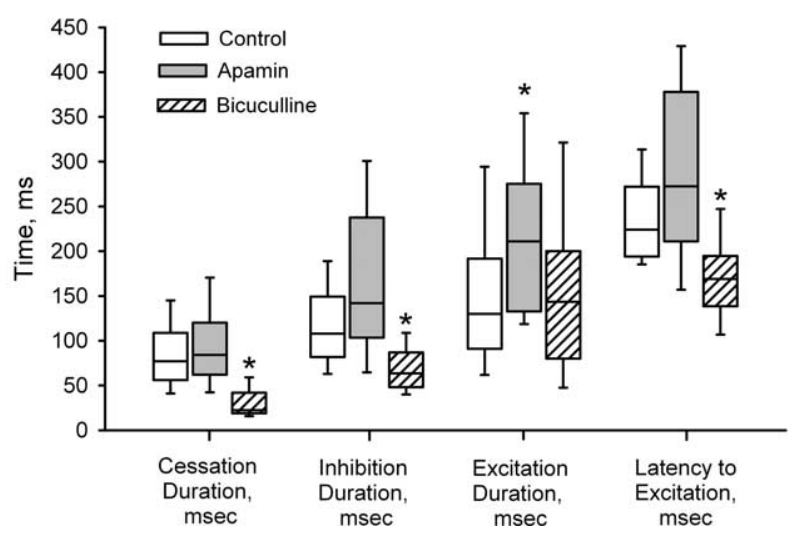

Figure 4. Effects of local application of apamin $(125 \mu \mathrm{M})$ and bicuculline $(20 \mathrm{~mm})$ on the response of $D A$ neurons to stimulation of the $\mathrm{LHb}$. $A$, Proportion of neurons responding to $\mathrm{LHb}$ stimulation by category. Note the increase in the number of $\mathrm{DA}$ neurons excited by $\mathrm{LHb}$ stimulation in the presence of bicuculline. $\boldsymbol{B}$, Box and whisker plots summarizing the effects of apamin and bicuculline on the duration of excitatory and inhibitory components of the response to stimulation. Data are expressed as median (line), interquartile (box), and 90th and 25th percentiles (whiskers). Asterisks denote a significant difference from control values (Dunn's method, $p<0.05)$. Error bars indicate mean $\pm \mathrm{SE}$.

1979; O'Brien and White, 1987; Kiyatkin and Rebec, 1998). However, blockade of these receptors on non-DA neurons would have increased their activity, enhancing the inhibitory drive on DA neurons, resulting in effects opposite to those observed here (Waszczak and Walters, 1980; Grace and Bunney, 1985; O’Brien and White, 1987; Paladini et al., 1999). As reported previously (Tepper et al., 1995), bicuculline-induced bursting was composed of a higher proportion of long bursts (three or more spikes) than "natural" (i.e., spontaneous) bursting activity and was accompanied by a concomitant reduction in spike doublets. Studies showing that bicuculline blocks SK $\mathrm{Ca}^{2+}$-activated $\mathrm{K}^{+}$channels (Seutin et al., 1997; Seutin and Johnson, 1999) could provide an explanation for these effects. By reducing SK current in DA neurons, bicuculline would be expected to prolong the intrinsically generated plateau potentials that appear to contribute to bursting activity in these cells (Ping and Shepard, 1999; Ji and Shepard, 2006). Indeed, local application of selective SK-channel blockers closely mimic the effects of bicuculline on DA activity in vivo (Waroux et al., 2005; Ji and Shepard, 2006). However, apamin clearly failed to modify the response of DA neurons to LHb stimulation. We can infer from these results that the ability of bicuculline to attenuate the inhibitory effects LHb stimulation derive from its actions at $\mathrm{GABA}_{\mathrm{A}}$ receptors and not SK channels. Although bicuculline blocked or attenuated the suppression of firing, it did not diminish the delayed excitation exhibited by some DA neurons. Selective blockade of the inhibitory component of the biphasic response increased the number of cells excited by $\mathrm{LHb}$ stimulation and reduced its latency to onset. These data suggest that the delayed excitation exhibited by some DA neurons is not a rebound phenomenon but a separate response mediated through an alternate neural pathway. The dorsal raphe, a major target of habenular efferents (Wang and Aghajanian, 1977; Herkenham and Nauta, 1979; Park, 1987; Lecourtier and Kelly, 2007), projects strongly to the ventral midbrain and has been shown to powerfully modulate the activity of DA neurons in the SN and VTA (Gervais and Rouillard, 2000). Additional studies will be required to determine whether this structure contributes to the delayed excitation observed in some DA neurons after LHb stimulation.

The precise nature of the connections between the LHb and ventral midbrain cannot be ascertained using the techniques used in this study. Nevertheless, it seems unlikely that the cessation in DA cell activity results from a monosynaptic input. As noted previously, the scope and magnitude of the response is out of proportion with the comparatively sparse innervation of the ventral midbrain by LHb efferents. GABA-containing neurons also comprise a small percentage of LHb neurons, and lesions of the structure fail to alter GABA levels in terminal regions (Vincent et al., 1980). On the other hand, the short latency between stimulus onset and cessation in DA cell firing indicates that no more than two neurons are likely to participate in the circuit. Results showing that $50 \%$ of the non-DA neurons in the midbrain are excited by LHb stimulation suggest that putative GABAergic neurons contribute to the cessation in DA cell activity. Of these cells, half exhibited a short-latency excitation that preceded the inhibition in DA cell activity and thus could have initiated it. Single shocks typically elicited several tightly clustered spikes that failed to collide with spontaneous action potentials and showed sufficient variation in latency ("jitter") to exclude the possibility that they were of antidromic origin. We estimated the distance between the LHb and midbrain at between 2.6 and $3.7 \mathrm{~mm}$ by computing the length of the hypotenuse of a right triangle, the adjacent sides of which represented the difference between the anteroposterior and dorsoventral coordinates of the stimulating and recording electrodes, respectively. Without accounting for synaptic or propagation delays, latency to onset of the excitation in non-DA neurons averaged $3.2 \mathrm{~ms}$, which is consistent with the estimated conduction velocity of LHb efferents (1.2-3.7 m/s) (Park, 1987). Although the average duration of the cessation in DA cell firing ( $\sim 85 \mathrm{~ms}$ ) exceeds the duration of the fast excitation recorded in non-DA cells $(\sim 5 \mathrm{~ms})$, synchronous activation of putative GABA-containing cells in the SN and VTA can powerfully inhibit DA neurons. Indeed, axons from single GABAergic neurons are estimated to give rise to an average of 80 terminal boutons within the pars reticulata (Mailly et al., 2003). The duration of the cessation in DA cell activity could have also been prolonged by the remaining $25 \%$ of non-DA neurons that exhibited a longerlatency excitation.

The notion that putative GABA-containing neurons contribute to LHb-induced inhibition of DA cell activity receives additional support from studies showing that LHb efferents are predominantly excitatory. Inputs to the dorsal raphe and ventral midbrain originate from the same region of the LHb and appear to use glutamate/aspartate as a neurotransmitter (Kalen et al., 1985, 1986). LHb neurons are devoid of GAD65 mRNA but ex- 
press high levels of the vesicular glutamate transporter vGluT2 (Brinschwitz et al., 2005). Although a small number of LHb neurons express GAD67 transcripts, cells labeled after injection of retrograde tracer into the VTA express only vGluT2 mRNA. Using anterograde tracing and double-label electron microscopy, these investigators also found that $>90 \%$ of $\mathrm{LHb}$-derived axon terminals in the VTA contact GABA-positive dendrites. These data provide strong evidence that efferents from the LHb are predominantly glutamatergic and that they preferentially target GABA-containing neurons in the ventral midbrain.

In summary, the present results demonstrate that activation of LHb efferents suppresses the activity of midbrain DA neurons through a $\mathrm{GABA}_{\mathrm{A}}$ receptor-mediated mechanism. The duration of the cessation and large number of DA neurons affected are consistent with results observed in behaving animals in response to the unanticipated loss of an expected reward (Ljungberg, 1992; Schultz et al., 1993; Tobler et al., 2003). These findings, together with hemodynamic changes in humans showing activation of the $\mathrm{LHb}$ in response to negative feedback, suggest that the habenulomesencephalic projections onto GABAergic neurons may provide an indirect inhibitory input to midbrain DA neurons that encodes unexpected negative outcomes (Ullsperger and von Cramon, 2003). As such, the LHb and its connections with midbrain neurons could represent a component of the neural network mediating reinforcement learning and error processing. Of course, this does not preclude the possibility that other inhibitory inputs to the ventral midbrain also participate in transiently suppressing the activity of DA neurons. Idiopathic or iatrogenic changes in this system could diminish an individual's ability to learn from negative feedback, a characteristic deficit observed in some DA-related disorders.

Note added in proof: Readers are referred to a paper by Matsumoto and Hikosake (2007), which appeared after this manuscript was accepted for publication, that describes the activity of habenular neurons in primates performing a reward-biased visual saccade task.

\section{References}

Andres KH, von During M, Veh RW (1999) Subnuclear organization of the rat habenular complexes. J Comp Neurol 407:130-150.

Bond CT, Maylie J, Adelman JP (2005) SK channels in excitability, pacemaking and synaptic integration. Curr Opin Neurobiol 15:305-311.

Brinschwitz K, Lommel R, Penkalla A, Goertzen A, Geisler S, Veh RW (2005) Glutamatergic fibers from the lateral habenula do not terminate on dopaminergic neurons in the ventral tegmental area. Soc Neurosci Abstr 31:891.823.

Bunney BS, Aghajanian GK (1976) The precise localization of nigral afferents in the rat as determined by a retrograde tracing technique. Brain Res 117:423-435.

Bunney BS, Walters JR, Roth RH, Aghajanian GK (1973) Dopaminergic neurons: effect of antipsychotic drugs and amphetamine on single cell activity. J Pharmacol Exp Ther 185:560-571.

Christoph GR, Leonzio RJ, Wilcox KS (1986) Stimulation of the lateral habenula inhibits dopamine-containing neurons in the substantia nigra and ventral tegmental area of the rat. J Neurosci 6:613-619.

Cuello AC, Emson PC, Paxinos G, Jessell T (1978) Substance P containing and cholinergic projections from the habenula. Brain Res 149:413-429.

Davey NJ, Ellaway PH, Stein RB (1986) Statistical limits for detecting change in the cumulative sum derivative of the peristimulus time histogram. J Neurosci Methods 17:153-166.

Emson PC, Cuello AC, Paxinos G, Jessell T, Iversen LL (1977) The origin of substance $\mathrm{P}$ and acetylcholine projections to the ventral tegmental area and interpeduncular nucleus in the rat. Acta Physiol Scand Suppl 452:43-46.

Ferraro G, Montalbano ME, Sardo P, La Grutta V (1996) Lateral habenular influence on dorsal raphe neurons. Brain Res Bull 41:47-52.
Fiorillo CD, Tobler PN, Schultz W (2003) Discrete coding of reward probability and uncertainty by dopamine neurons. Science 299:1898-1902.

Freeman AS, Meltzer LT, Bunney BS (1985) Firing properties of substantia nigra dopaminergic neurons in freely moving rats. Life Sci 36:1983-1994.

Gariano RF, Groves PM (1988) Burst firing induced in midbrain dopamine neurons by stimulation of the medial prefrontal and anterior cingulate cortices. Brain Res 462:194-198.

Geisler S, Andres KH, Veh RW (2003) Morphologic and cytochemical criteria for the identification and delineation of individual subnuclei within the lateral habenular complex of the rat. J Comp Neurol 458:78-97.

Gernert M, Fedrowitz M, Wlaz P, Loscher W (2004) Subregional changes in discharge rate, pattern, and drug sensitivity of putative GABAergic nigral neurons in the kindling model of epilepsy. Eur J Neurosci 20:2377-2386.

Gervais J, Rouillard C (2000) Dorsal raphe stimulation differentially modulates dopaminergic neurons in the ventral tegmental area and substantia nigra. Synapse 35:281-291.

Grace AA, Bunney BS (1979) Paradoxical GABA excitation of nigral dopaminergic cells: indirect mediation through reticulata inhibitory neurons. Eur J Pharmacol 59:211-218.

Grace AA, Bunney BS (1983) Intracellular and extracellular electrophysiology of nigral dopaminergic neurons-1. Identification and characterization. Neuroscience 10:301-315.

Grace AA, Bunney BS (1984) The control of firing pattern in nigral dopamine neurons: burst firing. J Neurosci 4:2877-2890.

Grace AA, Bunney BS (1985) Opposing effects of striatonigral feedback pathways on midbrain dopamine cell activity. Brain Res 333:271-284.

Guyenet PG, Aghajanian GK (1978) Antidromic identification of dopaminergic and other output neurons of the rat substantia nigra. Brain Res 150:69-84.

Herkenham M, Nauta WJ (1979) Efferent connections of the habenular nuclei in the rat. J Comp Neurol 187:19-47.

Horvitz JC, Stewart T, Jacobs BL (1997) Burst activity of ventral tegmental dopamine neurons is elicited by sensory stimuli in the awake cat. Brain Res 759:251-258.

Hugues M, Romey G, Duval D, Vincent JP, Lazdunski M (1982) Apamin as a selective blocker of the calcium-dependent potassium channel in neuroblastoma cells: voltage-clamp and biochemical characterization of the toxin receptor. Proc Natl Acad Sci USA 79:1308-1312.

Ji H, Shepard PD (2006) SK Ca2+-activated K+ channel ligands alter the firing pattern of dopamine-containing neurons in vivo. Neuroscience 140:623-633.

Kalen P, Karlson M, Wiklund L (1985) Possible excitatory amino acid afferents to nucleus raphe dorsalis of the rat investigated with retrograde wheat germ agglutinin and D-[3H] aspartate tracing. Brain Res 360:285-297.

Kalen P, Pritzel M, Nieoullon A, Wiklund L (1986) Further evidence for excitatory amino acid transmission in the lateral habenular projection to the rostral raphe nuclei: lesion-induced decrease of high affinity glutamate uptake. Neurosci Lett 68:35-40.

Khawaled R, Bruening-Wright A, Adelman JP, Maylie J (1999) Bicuculline block of small-conductance calcium-activated potassium channels. Pflügers Arch 438:314-321.

Kiyatkin EA, Rebec GV (1998) Heterogeneity of ventral tegmental area neurons: single-unit recording and iontophoresis in awake, unrestrained rats. Neuroscience 85:1285-1309.

Lecourtier L, Kelly PH (2007) A conductor hidden in the orchestra? Role of the habenular complex in monoamine transmission and cognition. Neurosci Biobehav Rev 31:658-672.

Lisoprawski A, Herve D, Blanc G, Glowinski J, Tassin JP (1980) Selective activation of the mesocortico-frontal dopaminergic neurons induced by lesion of the habenula in the rat. Brain Res 183:229-234.

Ljungberg T, Apicella P, Schultz W (1992) Responses of monkey dopamine neurons during learning of behavioral reactions. J Neurophysiol 67:145-163.

Mailly P, Charpier S, Menetrey A, Deniau JM (2003) Three-dimensional organization of the recurrent axon collateral network of the substantia nigra pars reticulata neurons in the rat. J Neurosci 23:5247-5257.

Matsumoto M, Hikosaka O (2007) Lateral habenula as a source of negative reward signals in dopamine neurons, in press.

Miller JD, Sanghera MK, German DC (1981) Mesencephalic dopaminergic unit activity in the behaviorally conditioned rat. Life Sci 29:1255-1263.

Morris G, Nevet A, Arkadir D, Vaadia E, Bergman H (2006) Midbrain do- 
pamine neurons encode decisions for future action. Nat Neurosci 9:1057-1063.

Nakahara H, Itoh H, Kawagoe R, Takikawa Y, Hikosaka O (2004) Dopamine neurons can represent context-dependent prediction error. Neuron 41:269-280.

Nishikawa T, Fage D, Scatton B (1986) Evidence for, and nature of, the tonic inhibitory influence of habenulointerpeduncular pathways upon cerebral dopaminergic transmission in the rat. Brain Res 373:324-336.

O'Brien DP, White FJ (1987) Inhibition of non-dopamine cells in the ventral tegmental area by benzodiazepines: relationship to A10 dopamine cell activity. Eur J Pharmacol 142:343-354.

Paladini CA, Celada P, Tepper JM (1999) Striatal, pallidal, and pars reticulata evoked inhibition of nigrostriatal dopaminergic neurons is mediated by GABA(A) receptors in vivo. Neuroscience 89:799-812.

Pan WX, Hyland BI (2005) Pedunculopontine tegmental nucleus controls conditioned responses of midbrain dopamine neurons in behaving rats. J Neurosci 25:4725-4732.

Pan WX, Schmidt R, Wickens JR, Hyland BI (2005) Dopamine cells respond to predicted events during classical conditioning: evidence for eligibility traces in the reward-learning network. J Neurosci 25:6235-6242.

Park MR (1987) Monosynaptic inhibitory postsynaptic potentials from lateral habenula recorded in dorsal raphe neurons. Brain Res Bull 19:581-586.

Phillipson OT (1979) Afferent projections to the ventral tegmental area of Tsai and interfascicular nucleus: a horseradish peroxidase study in the rat. J Comp Neurol 187:117-143.

Ping HX, Shepard PD (1999) Blockade of SK-type $\mathrm{Ca}^{2+}$-activated $\mathrm{K}^{+}$ channels uncovers a $\mathrm{Ca}^{2+}$-dependent slow afterdepolarization in nigral dopamine neurons. J Neurophysiol 81:977-984.

Richards CD, Shiroyama T, Kitai ST (1997) Electrophysiological and immunocytochemical characterization of GABA and dopamine neurons in the substantia nigra of the rat. Neuroscience 80:545-557.

Satoh T, Nakai S, Sato T, Kimura M (2003) Correlated coding of motivation and outcome of decision by dopamine neurons. J Neurosci 23:9913-9923.

Schultz W, Apicella P, Ljungberg T (1993) Responses of monkey dopamine neurons to reward and conditioned stimuli during successive steps of learning a delayed response task. J Neurosci 13:900-913.

Schultz W, Dayan P, Montague PR (1997) A neural substrate of prediction and reward. Science 275:1593-1599.

Seutin V, Johnson SW (1999) Recent advances in the pharmacology of quaternary salts of bicuculline. Trends Pharmacol Sci 20:268-270.
Seutin V, Scuvee-Moreau J, Dresse A (1997) Evidence for a non-GABAergic action of quaternary salts of bicuculline on dopaminergic neurones. Neuropharmacology 36:1653-1657.

Shepard PD, Holcomb HH, Gold JM (2006) The presence of absence: habenular regulation of dopamine neurons and the encoding of negative outcomes. Schizophr Bull 32:417-421.

Smith ID, Grace AA (1992) Role of the subthalamic nucleus in the regulation of nigral dopamine neuron activity. Synapse 12:287-303.

Steffensen SC, Svingos AL, Pickel VM, Henriksen SJ (1998) Electrophysiological characterization of GABAergic neurons in the ventral tegmental area. J Neurosci 18:8003-8015.

Steward O, Tomasulo R, Levy WB (1990) Blockade of inhibition in a pathway with dual excitatory and inhibitory action unmasks a capability for LTP that is otherwise not expressed. Brain Res 516:292-300.

Tepper JM, Martin LP, Anderson DR (1995) GABA $_{\mathrm{A}}$ receptor-mediated inhibition of rat substantia nigra dopaminergic neurons by pars reticulata projection neurons. J Neurosci 15:3092-3103.

Tobler PN, Dickinson A, Schultz W (2003) Coding of predicted reward omission by dopamine neurons in a conditioned inhibition paradigm. J Neurosci 23:10402-10410.

Ullsperger M, von Cramon DY (2003) Error monitoring using external feedback: specific roles of the habenular complex, the reward system, and the cingulate motor area revealed by functional magnetic resonance imaging. J Neurosci 23:4308-4314.

Vincent SR, Staines WA, McGeer EG, Fibiger HC (1980) Transmitters contained in the efferents of the habenula. Brain Res 195:479-484.

Wang RY (1981) Dopaminergic neurons in the rat ventral tegmental area. I. Identification and characterization. Brain Res Rev 3:123-140.

Wang RY, Aghajanian GK (1977) Physiological evidence for habenula as major link between forebrain and midbrain raphe. Science 197:89-91.

Waroux O, Massotte L, Alleva L, Graulich A, Thomas E, Liegeois JF, ScuveeMoreau J, Seutin V (2005) SK channels control the firing pattern of midbrain dopaminergic neurons in vivo. Eur J Neurosci 22:3111-3121.

Waszczak BL, Walters JR (1980) Intravenous GABA agonist administration stimulates firing of A10 dopaminergic neurons. Eur J Pharmacol 66:141-144.

Waszczak BL, Lee EK, Ferraro T, Hare TA, Walters JR (1984) Single unit responses of substantia nigra pars reticulata neurons to apomorphine: effects of striatal lesions and anesthesia. Brain Res 306:307-318. 